\title{
Acidentes de trabalho atendidos no pronto socorro de um hospital do Extremo Sul Catarinense
}

\author{
Fernanda Minatto*, Sônia Maria Corrêa, M.Sc.**, Mágada Tessmann Schwalm**, Luciane Bisognin \\ Ceretta**** $^{* * * 1}$
}

${ }^{*}$ Graduada em enfermagem pela UNESC (Universidade do Extremo Sul Catarinense) $\nabla$ Criciúma/SC, **Docente do Curso de Enfermagem - UNESC, ***Doutoranda em Ciências da Saúde - Coordenadora do Curso de Enfermagem - UNESC, ****Doutoranda em Ciências da Saúde - Diretora da Unidade Acadêmica da Saúde (UNASAU) - UNESC

\section{Resumo}

O estudo teve como objetivo caracterizar os acidentes de trabalho atendidos no pronto socorro de um Hospital do Extremo Sul Catarinense nos aspectos relacionados às variáveis: incidência por sexo, faixa etária, espécies de acidente de trabalho, bem como as lesôes que mais acometem os trabalhadores e a área profissional mais afetada. Trata-se de uma pesquisa de abordagem quantitativa, com corte transversal, documental do tipo retrospectivo. Os dados foram obtidos através da análise das fichas de pronto atendimento do pronto socorro. Verificou-se 5.762 fichas do mês de julho de 2010, nas quais foram constatados 31 acidentes de trabalho típico, o que significou $0,53 \%$ em relação a esse total de fichas analisadas. Entre as pessoas que sofreram acidente de trabalho, 90,32\% eram do sexo masculino e 9,68\% do sexo feminino. A idade variou entre 18 e 53 anos, sendo que a faixa etária predominante foi 24 a 29 anos (29,03\%). Com relação às espécies de acidentes de trabalho, todos foram típicos, sendo que as lesôes mais encontradas foram associadas a trauma de mão com $36 \%$, seguido de trauma ocular com 24\%; dentre a área profissional de maior incidência, destacou-se a construção civil, com $20 \%$ na profissão de pedreiro. A melhoria das informaçóes constitui uma das prioridades à qual deve ser concedida atenção especial. Uma das medidas, neste sentido, seria a promoção do registro contínuo padronizado e adequado das informaçôes, de modo a possibilitar estudos e elaboração de estratégias de intervenção acerca dos acidentes de trabalho. A partir dos resultados da pesquisa verificou-se a importância das anotaçóes dos profissionais da saúde no sentido de obter dados fidedignos nas pesquisas realizadas.

Palavras-chave: saúde do trabalhador, acidentes de trabalho, registros.

\section{Abstract \\ Accidents at work treated in an emergency unit of a hospital of Extremo Sul Catarinense}

The study aimed to characterize work-related accidents treated in an emergency unit of a hospital of Extremo Sul Catarinense in aspects related to the following variables: incidence by sex, age, types of accidents at work, as well as the most common workplace injuries and professional area most affected. This is a quantitative study with cross-sectional, retrospective and documentary approach. Data were obtained by analyzing medical records of the emergency unit. 5762 records related to July 2010 were verified, and 31 events were classified as typical work accidents, which represented $0.53 \%$ compared to the 
total number of medical records analyzed. Among those who had suffered accidents at work, $90.32 \%$ were male and $9.68 \%$ females. Age ranged from 18 and 53 years, and the predominant age group was 24 to 29 years old (29.03\%). With respect to the types of work accidents, all of them were typical, and the most common injuries were hand trauma (36\%), followed by ocular trauma (24\%); concerning professional area, the construction had the highest incidence of injuries, and $20 \%$ were bricklayer professionals. Special attention should be given to improvement of information. One step in this direction should be the standardization of medical records and to provide continuous and adequate information to enable research and development of intervention strategies on accidents at work. The results showed the importance of accurate notes carried out by health professionals in order to obtain reliable data in studies.

Key-words: occupational health, accidents at work, records.

\section{Resumen}

\section{Accidentes de trabajo asistidos en servicio de emergencias de un hospital del Extremo Sur Catarinense}

El objetivo de este estudio fue caracterizar los accidentes de trabajo asistidos en el servicio de emergencias de un hospital del Extremo Sul de Santa Catarina en aspectos relacionados con las variables: incidencia por sexo, edad, tipos de accidentes, así como las lesiones que más afectan a los profesionales y el área profesional más afectada. Se trata de una investigación cuantitativa, transversal, documental del tipo retrospectiva. Los datos se obtuvieron mediante el análisis de los registros clínicos del servicio de emergencia. 5.762 registros correspondientes al mes de julio de 2010 fueron verificados, y 31 accidentes de trabajo típico fueron encontrados, lo que representa un $0,53 \%$ en comparación con el número total de registros analizados. Entre los que han sufrido accidentes en el trabajo, un $90.32 \%$ eran hombres y $9,68 \%$ mujeres. La edad osciló entre 18 y 53 ańos, y el grupo de edad predominante fue el de 24 a 29 ańos (29,03\%). Con respecto a los tipos de accidentes, todos eran típicos, y en la mayoría se encontraron lesiones traumáticas de la mano (36\%), seguida del trauma ocular (24\%); el área profesional de mayor incidencia ha sido la construcción, con un $20 \%$ en la profesión de albañil. La mejora de la información será una prioridad que debe darse una atención especial. Una de las medidas en este sentido seria un sistema de registro clínico estandarizado y promover información continua y adecuada para permitir la investigación y el desarrollo de estrategias de intervención acerca de los accidentes en el trabajo. A partir de los resultados de la investigación se verificó la importancia de las anotaciones de los profesionales de la salud para obtener datos fiables en los estudios.

Palabras-clave: salud ocupacional, accidentes de trabajo, registros.

\section{Introdução}

Os acidentes de trabalho na atualidade têm se confirmado um problema de saúde pública grave $\mathrm{e}$ de grande magnitude que transcende e reflete inteiramente nos trabalhadores, o que exige medidas preventivas na tentativa de tornar mínimo o problema.

$\mathrm{O}$ acontecimento infeliz e violento que atinge o trabalhador no exercício da atividade laborativa ou a doença profissional desdobra-se em graves consequências, tais como o afastamento do empregado de sua atividade e a carga econômica sofrida pelos cofres públicos em razão dos benefícios de prestação continuada a serem pagos em função do infortúnio [1].

Dados da Organização Internacional do Trabalho (OIT- 2002) mostram que em média dez pessoas morrem todos os dias no exercício de sua atividade profissional, ou seja, uma a cada duas horas e meia, encontrando-se o Brasil em décimo lugar no ranking dos países com o maior número de acidentes de trabalho. De acordo com a OIT só as causas naturais matam mais no mundo do que os acidentes de trabalho. As razóes para explicar o elevado número de ocorrências dos acidentes são as mais diversas, envolvendo falhas nos projetos dos sistemas de trabalho, dos equipamentos, das ferramentas e deficiência nos processos de manutenção dos diversos elementos componentes do trabalho. Ocupando lugar de destaque como causa dos acidentes de trabalho encontra-se o fator humano, compreendendo vivências de prazer e sofrimento interferindo no comportamento de risco, características psicossociais do trabalhador, atitudes negativas para com as atividades prevencionista, aspectos da personalidade, falta de atenção, entre outras [2].

Acidente de trabalho é o que ocorre pelo exercício do trabalho a serviço da empresa ou pelo exercício do trabalho dos segurados, provocando lesão corporal ou perturbação funcional que cau- 
se a morte, a perda ou reduçáo, temporária ou permanente, da capacidade para o trabalho [3]. A classificação e identificação dos acidentes do trabalho, Estatísticas Oficiais da Previdência Social e Ministério do Trabalho, basicamente, são divulgadas nas quatro espécies consideradas principais, sejam elas: o acidente típico, as doenças ocupacionais, acidente de trajeto e concausas [4]. O acidente típico decorre do exercício do trabalho, ocasionando a lesão, a qual leva à ocorrência de uma incapacidade total ou parcial, permanente ou temporária [5]. Entretanto, o mesmo ressalta que o acidente típico se percebe o exato momento da lesão podendo ser estabelecido o tempo entre uma lesão e outra, diferente da doença ocupacional. Oliveira [4] garante que o acidente é um fato que provoca lesão, já a enfermidade profissional é um estado patológico ou mórbido, o qual provoca perturbação da saúde do trabalhador. Portanto os dois possuem características diferentes, sendo que um é possível visualizar de imediato enquanto o outro é em longo prazo. No que diz respeito ao acidente de trajeto, é conhecido como in itinere, o qual é entendido como aquele ocorrido entre o caminho do trabalhador de casa para o seu trabalho, e vice-versa. Entretanto, alguns requisitos são indispensáveis para que se configure o acidente in itinere, sejam eles: que o percurso habitual não tenha sido interrompido, isto é, que haja uma concordância cronológica; e que o percurso não tenha sido alterado para atendimento de interesses particulares, ou seja, que exista concordância topográfica, pois o desvio de trajeto descaracteriza $o$ acidente [6]. Temos também as concausas, que não é um termo muito conhecido entre os trabalhadores, mas que é tratada na Lei no 8213/91 no seu artigo 21 . As concausas subsistem em condiçóes as quais "concorrem para o agravamento do dano, mas que não têm a virtude de excluir o nexo causal desencadeado pela conduta principal, nem de, por si sós, produzir o dano" [7]. As concausas podem ser preexistentes, supervenientes ou concomitantes à causa que desencadeou o acidente do trabalho ou doença ocupacional [4].

Pessoas acometidas por acidentes de trabalho constituem uma parte significativa dos atendimentos em serviços médicos, especialmente nos serviços de emergência. Os acidentes de trabalho que chegam ao hospital constantemente são graves e crescentes. Assim, este cenário justifica a investigação na busca da compreensão, descrevendo o perfil dessas ocorrências em relação a características dos acidentados, considerando-se que grande parte dos trabalhadores que sofrem acidentes de trabalho deve ser encaminhada aos serviços de emergência, independentemente do seu tipo de vínculo empregatício.

As informaçóes obtidas através deste estudo são de fundamental importância no sentido de conhecer a realidade frente aos acidentes de trabalho e direcionar programas de educação em saúde nas empresas e também dar visibilidade a este problema chamando a atenção dos profissionais de saúde para a notificação destes agravos. Os resultados deste estudo pode também contribuir com o direcionamento de açôes das Unidades Básicas de Saúde junto às empresas de sua área de abrangência, no sentido de buscar minimizar ao máximo estas ocorrências.

\section{Material e métodos}

A abordagem metodológica apresentada é de caráter quantitativo, retrospectivo, descritivo com corte transversal, realizada por meio de pesquisa de dados secundários, conhecida como pesquisa documental. A coleta de dados ocorreu entre os meses de março e abril de 2011 e foi efetuada por meio da análise das fichas de pronto atendimento do pronto socorro, do mês de Julho de 2010 , evidenciando-se a ocorrência de acidentes de trabalho no mês, segundo sexo, faixa etária, espécies de acidente de trabalho, bem como as lesóes mais encontradas nos trabalhadores e a área profissional mais afetada.

O estudo foi realizado no Serviço de Arquivamento Médico (SAME) de um hospital de grande porte e alta complexidade da Regiáo Sul do Estado de Santa Catarina. O referido hospital conta com a estimativa de 7.000 atendimentos ao mês.

A análise de dados quantitativos foi realizada a partir da inserção em banco de dados, no programa Software Statistical Package for the Sciences (SPSS) 17.0 com interpretaçáo dos resultados de acordo com a literatura disponível.

Os critérios para a inclusão do estudo foram as fichas identificadas como acidente de trabalho, e fichas de pacientes atendidos no mês de julho de 2010, já os critérios para exclusão do estudo foram as fichas de outros meses e anos, e fichas que não tinham identificação de acidente de trabalho. O Termo de Consentimento Livre e Esclarecido foi assinado pelo administrador do hospital antes da pesquisa. O projeto teve aprovação do CEP da instituição hospitalar com parecer número 196/2011. 


\section{Resultados}

Verificou-se 5.762 fichas do mês de julho de 2010. Das 5.762 fichas avaliadas, foram constatados 31 acidentes de trabalho típico, o que significa $0,53 \%$ em relação a esse total de fichas.

\section{Perfil dos pacientes atendidos no pronto socorro}

A figura 1 nos mostra o sexo dos pacientes atendidos no pronto socorro, que foram considerados como acidente de trabalho típico. Constatou-se que $90,32 \%$ dos pacientes eram do sexo masculino e $9,68 \%$ do sexo feminino.

Figura 1 - Sexo dos pacientes atendidos no pronto socorro.

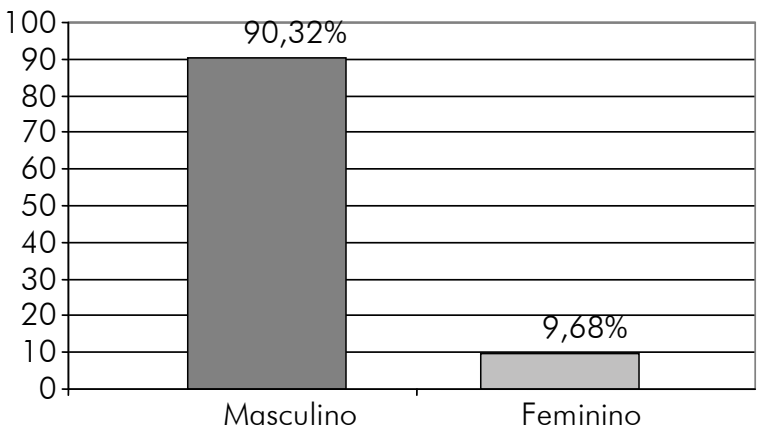

A clientela de acidentados era predominantemente masculina, demonstrando que na divisão social do trabalho ou mesmo na divisão do trabalho existe uma tendência para atribuir aos homens às tarefas mais pesadas e perigosas, responsáveis por acidentes mais graves [8].

A amostra estudada assemelha-se aquela encontrada na pesquisa realizada por Cardoso [9], sobre a análise de acidentes de trabalho na Cidade de Araranguá no segundo semestre de 2009, a qual constatou que $100 \%$ dos acidentes ocorreram com trabalhadores do sexo masculino.

$\mathrm{Na}$ figura 2 percebe-se que a idade variou entre 18 e 53 anos, sendo que $29,03 \%$ dos pacientes estavam na faixa etária de 24 a 29 anos de idade, considerados adultos jovens.

Dados da Previdência Social mostram que a grande maioria dos acidentes ocorre em homens, na faixa etária entre 24 a 29 anos [10].

Os resultados corroboram os obtidos por Campoamor [11] que, em seu estudo sobre ocorrência de acidentes entre trabalhadores de uma indústria frigorífica do Estado de São Paulo, verificou que a faixa etária com maior prevalência de acidentes foi entre 25 a 40 anos (41,5\%). Essa faixa etária, aliás, caracteriza o grupo de pessoas que se concentra a maior força de trabalho.

Figura 2 - Faixa etária dos pacientes atendidos no pronto socorro

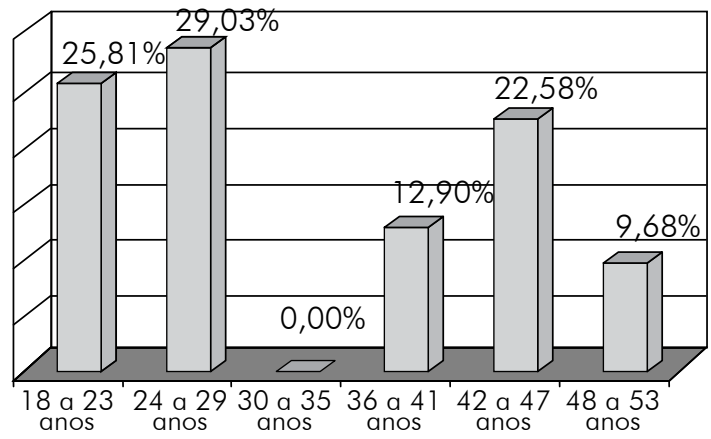

Segundo Santana et al. [12], os acidentes de trabalho acometem mais comumente pessoas jovens no início da vida laboral, época em que esses agravos podem afetar com grande dimensão a capacidade produtiva e econômica do país.

Conforme trabalho realizado por Siviero et al. [13], que caracterizou os estados brasileiros quanto a fatores associados aos acidentes de trabalho no Brasil no ano de 2004, constatou que nos estados de Roraima, Santa Catarina e no Amazonas, os acidentes acometeram trabalhadores mais jovens, principalmente até os 29 anos de idade. Isto se justifica por existir uma grande participação dessa faixa etária na força de trabalho, contudo, nas atividades que apresentam maiores riscos.

\section{Profissáo dos trabalhadores e lesóes}

A profissão dos trabalhadores não está inserida nos dados de identificação da ficha de atendimento do pronto socorro. Portanto a profissão foi especificada em algum momento nos registros escritos, efetuados por profissionais da área da saúde, sendo que $48,39 \%$ não constavam deste dado, conforme destacado na Tabela I.

Diante dos resultados obtidos, de modo geral, considera-se de extrema importância que tenhamos registros completos, tanto de identificação do sujeito quanto da descrição do acidente em si, como forma de identificar os maiores riscos laborais.

Possivelmente outros pacientes que foram atendidos tiveram acidentes de trabalho, no entanto não se conseguiu estabelecer nexo, através da leitura 
Tabela I - Profissão dos trabalhadores e lesões.

\begin{tabular}{|c|c|c|c|c|c|c|c|}
\hline \multirow{3}{*}{ Lesões } & \multicolumn{5}{|c|}{ Profissão } & \multirow{3}{*}{$\begin{array}{c}\text { Ausência do } \\
\text { dado }\end{array}$} & \multirow{3}{*}{ Total } \\
\hline & \multirow[b]{2}{*}{ Soldador } & \multirow[b]{2}{*}{ Pedreiro } & \multirow[b]{2}{*}{ Téc. Enf. } & \multirow[b]{2}{*}{ Mecânico } & \multirow[b]{2}{*}{ Mineiro } & & \\
\hline & & & & & & & \\
\hline Trauma Ocular & 5 & 0 & 0 & 1 & 0 & 1 & 7 \\
\hline & & & & & & & $22,58 \%$ \\
\hline Queda de Andaime & 0 & 2 & 0 & 0 & 0 & 0 & 2 \\
\hline & & & & & & & $6,44 \%$ \\
\hline Trauma de Mão & 0 & 2 & 0 & 0 & 0 & 9 & 11 \\
\hline & & & & & & & $35,48 \%$ \\
\hline Torção do Joelho & 0 & 0 & 0 & 0 & 0 & 1 & 1 \\
\hline & & & & & & & $3,23 \%$ \\
\hline Trauma de Clavícula & 0 & 0 & 0 & 0 & 0 & 1 & 1 \\
\hline & & & & & & & $3,23 \%$ \\
\hline Trauma Cervical & 0 & 1 & 0 & 0 & 0 & 0 & 1 \\
\hline & & & & & & & $3,23 \%$ \\
\hline Trauma de Crânio & 0 & 1 & 0 & 0 & 0 & 2 & 3 \\
\hline & & & & & & & $9,68 \%$ \\
\hline Trauma de Bacia & 0 & 0 & 0 & 0 & 1 & 0 & 1 \\
\hline & & & & & & & $3,23 \%$ \\
\hline Trauma de Face & 0 & 0 & 0 & 0 & 1 & 0 & 1 \\
\hline & & & & & & & $3,23 \%$ \\
\hline Queimaduras & 0 & 0 & 0 & 1 & 0 & 1 & 2 \\
\hline & & & & & & & $6,44 \%$ \\
\hline Perfuro Cortante & 0 & 0 & 1 & 0 & 0 & 0 & 1 \\
\hline & & & & & & & $3,23 \%$ \\
\hline Total & 5 & 6 & 1 & 2 & 2 & 15 & 31 \\
\hline & $16,13 \%$ & $19,35 \%$ & $3,23 \%$ & $6,45 \%$ & $6,45 \%$ & $48,39 \%$ & $100 \%$ \\
\hline
\end{tabular}

das fichas, sobre a ocupação da pessoa e o fato de o acidente ocorrido ser relacionado ao trabalho, devido à pobreza de anotaçôes, nesse sentido.

A qualidade das anotaçôes nas fichas de atendimento se apresenta como importante elemento determinante da eficiência de serviço de emergência [14].

A Figura 3 nos revela que a área profissional de maior incidência de acidente de trabalho foi na área da construção civil, com 19,35\% na profissão de pedreiro.

Estes dados assemelham-se parcialmente aos resultados da pesquisa de Cardoso [10] que afirma que a profissáo com maior número de acidentes na construção civil foi a de pedreiro com $28,6 \%$ do total de acidentes.

Estudo realizado com trabalhadores da construçáo civil evidenciou que $87 \%$ dos acidentes de trabalho ocorreram entre serventes, pedreiros e carpinteiros [15].

Silveira et al. [16] em pesquisa realizada num Pronto Atendimento de um Hospital Universitário, em relação à incidência de acidentes de trabalho atendidos, verificou que $24,27 \%$ eram trabalhadores da construçáo civil, que é considerado bastante representativo frente às diversas profissóes. "A Indústria da Construção Civil mantém elevados índices de Acidentes de Trabalho apesar de esforços governamentais, empresariais e sindicais no sentido de reduzi-los" [16].

Figura 3 - Profissão dos pacientes acometidos por acidente de trabalho

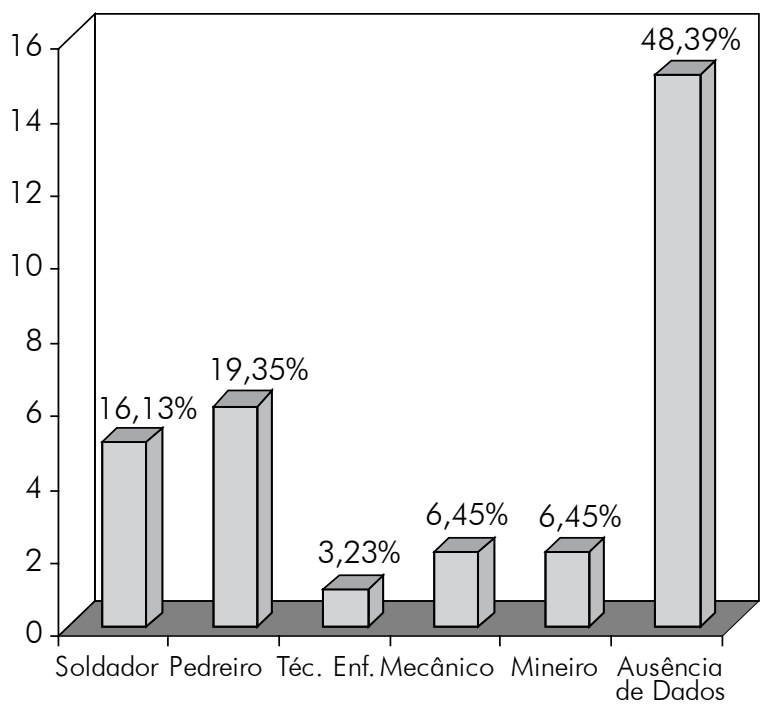


Conforme estudo de Carvalho et al. [17], a construção civil produz uma grande frequência de acidentes. $42 \%$ dos trabalhadores referem que já sofreram pelos menos um acidente: trabalhando como pedreiro $(28,5 \%)$, carpinteiro e marceneiro $(28,5 \%)$, servente $(24 \%)$, ferreiro $(9,5 \%)$, eletricista $(9,5 \%)$.

A área da construção civil teve um crescimento bastante acentuado no nosso país nos últimos anos, mas continua liderando os índices de acidente de trabalho, portanto é de fundamental importância que estejamos atentos com relação à evolução de novas formas de prevenção nesta área.

Com relação às espécies de acidentes de trabalho, todos foram típicos, isto é, aqueles que ocorrem no local de trabalho, sendo que as lesóes mais encontradas nos pacientes com acidente de trabalho foram associadas a trauma de mão $35,48 \%$, seguido de trauma ocular com $22,58 \%$, conforme nos mostra a figura 4 .

Figura 4 - Lesões encontradas.

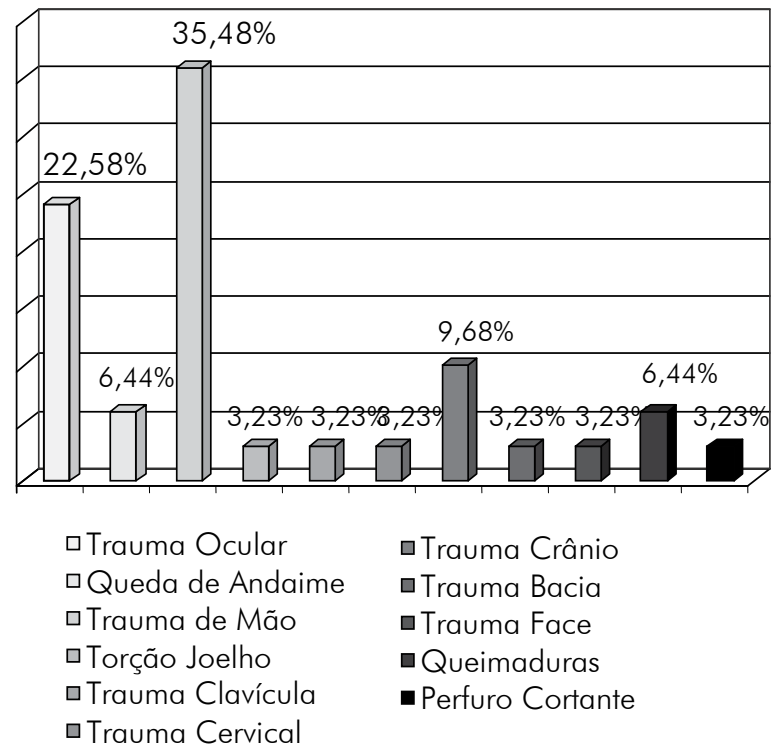

Guarizo [18], em estudo realizado no município de Amparo, São Paulo, descreveu os acidentes do trabalho registrados na Previdência Social de 2005 a 2007 e constatou que nos acidentes típicos, as regióes do corpo mais atingidas foram mão (inclusive dedos) com 45,8\%, membro inferior (exceto pé) com $16,3 \%$ e membro superior (exceto mão) com $12,8 \%$.

Fonseca et al. encontraram, em um estudo de 1.000 casos de acidentes de trabalho, 93,2\% de homens com lesão traumática da mão. "Os valores encontrados vão ao encontro da experiência clínica, em que é sabido que o homem, mais sujeito a situaçóes de risco no trabalho, no trânsito e também a casos de violência urbana, está mais propenso a sofrer acidentes na mão" [19].

Dados esses que se assemelham aos obtidos por Souza et al. [20] em um estudo realizado no Serviço de Reabilitação de Máo do Hospital Maria Amélia Lins (HMAL), o qual constatou incidência de 33,5\% de envolvimento das mãos em acidentes de trabalho no período de janeiro 2004 a dezembro 2005.

Estudo realizado na região da Zona Norte de Sáo Paulo, em que foram analisadas 2.339 CAT, no período de outubro a dezembro de 1988, observou que os acidentes com membros superiores representaram $42,1 \%$ do total de acidentes estudados, sendo que as mãos e os dedos foram nas regiōes mais afetadas, correspondendo a $31,5 \%$ dos acidentes analisados [21].

\section{Outros achados importantes}

Este tópico se fez necessário devido aos problemas encontrados com relação às informaçóes nas fichas pesquisadas. Aqui serão apresentados alguns dados que poderiam ser relatados como acidentes de trabalho se houvesse anotaçóes dos profissionais de saúde responsáveis pelo atendimento, ou seja, descrição dos fatos ocorridos.

Estes dados estão classificados neste tópico como: dor relacionada à atividade laboral e acidentes indefinidos. Se pudéssemos caracterizar estes dados como acidentes de trabalho, o resultado final do índice de acidentes do mês de julho de 2010 seria de $1,72 \%$ e não de $0,53 \%$.

Por exemplo, foram encontradas em algumas fichas, queixas de dor, as quais estavam relacionadas a profissão exercida pelo paciente, porém sem maiores descriçóes, mas que poderiam ter sido ocasionadas na atividade laboral. Foram identificados $0,34 \%$ relatos de dor, sendo que $50 \%$ dos pacientes estavam especificados a profissáo e $50 \%$ não tinham nenhuma especificação da ocupação exercida. Entre estas anotaçóes observamos que 55\% dos pacientes referiram dor lombar com as profissóes de pedreiro, faxineiras e doméstica. 15\% com dor no ombro relacionado às profissóes de pintor e doméstica. $15 \%$ com dor no cotovelo relacionado à área da construção civil, com a profissão de pedreiro. 10\% com dor na máo sendo que 5\% ocupavam cargo de 
operadora de caixa e 5\% náo constava a profissão. $5 \%$ dor de cabeça devido inalaçáo de permanganato, que também não tinha profissão descrita.

Já, os acidentes considerados indefinidos, ou seja, que náo foram identificados como acidentes de trabalho nas fichas de atendimento, mas que poderiam caracterizar-se como tal em algum momento nos registros escritos, efetuados por profissionais $\mathrm{da}$ área da saúde, foram encontrados 49 acidentes indefinidos, o que significa $0,85 \%$ em relação ao total de fichas analisadas. Estes acidentes considerados indefinidos tiveram como, por exemplo, queda de escada, trauma em mão (esmagamento em esteira), trauma em mão (trancou mão na máquina), trauma em região escapular (madeira), trauma em crânio (queda de andaime), trauma em queixo (peça mecânica), entre outros.

\section{Conclusão}

A falta de informações no documento pesquisado, obviamente, foi um dos vieses encontrados, pois quase a totalidade das fichas analisadas estava preenchida de forma inadequada, ou seja, não continha registro da origem do acidente, e fatores que poderiam caracterizar como acidente de trabalho ou não, o que comprometeu diretamente a qualidade das informaçóes do estudo.

A partir dos resultados desta pesquisa podemos constatar que os acidentes de trabalho aconteceram com maior frequência em adultos jovens do sexo masculino na área da construção civil. Porém pode ser questionado o número total dos acidentes de trabalho, já que poderia ser bem maior se as anotaçóes no documento pesquisado estivessem completas.

Um dos grandes problemas na área da saúde do trabalhador foi a subnotificação e podemos observar, através do presente estudo, que esta subnotificação pode ser devido ao simples fato de não se ter informaçóes básicas como, por exemplo, a ocupação do trabalhador atendido nos serviços de pronto atendimento. Possivelmente outros pacientes foram atendidos com acidentes de trabalho, além dos 31constatados, no entanto náo se conseguiu estabelecer nexo, através da leitura das fichas, sobre a ocupaçáo da pessoa e também a falta de clareza nas anotaçóes dos fatos ocorridos.

Verificou-se a importância das anotaçóes dos profissionais da saúde no sentido de obter dados fidedignos nas pesquisas realizadas.

A melhoria das informaçóes constituirá uma das prioridades à qual deverá ser concedida atenção especial. A identificação e implementação de mecanismos que possibilitem a ampliação da cobertura de informação relativa aos acidentes de trabalho será um passo importante para conhecer melhor a realidade de acidentes de trabalho no conjunto dos trabalhadores, ainda que seja necessário o desenvolvimento de pesquisas epidemiológicas para complementação desses resultados.

\section{Referências}

1. Andrade DS. Acidente do trabalho. Rio de Janeiro: ADCOAS; $1994.7 \mathrm{p}$.

2. Di Lascio CHR. A psicologia no trabalho. Revista Contato 2001;23(113):11.

3. Moraes GA. Normas Regulamentadoras Comentadas: Legislação de Segurança e Saúde no Trabalho. 5a ed. Rio de Janeiro: Giovanni Moraes de Araujo; 2005.

4. Oliveira SG. Indenizaçôes por acidente do trabalho ou doença ocupacional. 4a ed. São Paulo: LTr; 2008.

5. Jorge Neto FF, Cavalcante JQP. Direito do trabalho. $4 \mathrm{a}$ ed. Rio de Janeiro: Lumen Juris; 2008. 849 p.

6. Gonçalves DI. Acidente do Trabalho. Revista de Direito Social 2001; 3.

7. Cavalieri Filho S. Programa de responsabilidade civil. 8a ed. São Paulo: Atlas; 2008.

8. Azzi SGPS. Diagnósticos de acidentes no trabalho ocorridos na indústria química do Estado de Goiás S/A-IQUEGO [Dissertação]. Goiânia: Universidade Católica de Goiás; 2009. 195f.

9. Cardoso TM. Análise de acidentes de trabalho na cidade de Araranguá no segundo semestre de 2009 [TCC]. Criciúma: Universidade do Extremo Sul Catarinense; 2010. $68 \mathrm{f}$.

10. Brasil. Ministério da Previdência e Assistência Social. Anuário Estatístico da Previdência Social - AEPS. Brasília: Ministério da Previdência e Assistência Social; 2006.

11. Campoamor MM. Estudo da ocorrência de acidentes entre trabalhadores de uma indústria frigorífica do Estado de São Paulo. [Dissertação]. Ribeirão Preto: Escola de Enfermagem de Ribeirão Preto; 2006. 96f.

12. Santana VS, Silva M, Albuquerque-Oliveira PR, Barbosa-Branco A, Nobre LCC. Mortalidade, anos potenciais de vida perdidos e incidência de acidentes de trabalho na Bahia, Brasil. Cad Saúde Pública 2007;23(11):2643-52.

13. Siviero PCL, Queiroz BL, Wajnman S, Machado CJ. Acidentes do trabalho no Brasil, 2004: Um estudo ecológico utilizando componentes principais. Belo Horizonte: UFMG; 2009.

14. Avanzi MP, Silva CRG. Diagnósticos mais freqüentes em Serviço de Emergência para adulto de um Hospital Universitário. Rev Ciênc Méd (Campinas) 2005;14(2):175-85.

15. Costella M, Cremonini R, Guimarães L. Análise dos acidentes de trabalho ocorridos na atividade de construçáo civil no Rio Grande do Sul em 1996 e 1997. In: Encontro Nacional de Engenharia de Produção. 
Niterói, RJ. Niterói: Universidade Federal Fluminense; 1998.

16. Silveira CA, Robazzi MLCC, Walter EV, Marzial MHP. Acidentes de trabalho na construção civil identificados através de prontuários hospitalares. Rem Rev Esc Minas 2005;58(1):39-44.

17. Carvalho RJM. Condiçóes de trabalho na construção de edificaçóes no triângulo Crajubar/CE. In: XVIII Encontro Nacional de Engenharia de Produção. 6 p. Rio de Janeiro; 1998.

18. Guarizo ALG. Epidemiologia dos acidentes de trabalho registrados na previdência social do Município de Amparo-SP, no período de 2005 a 2007. [Dissertação].
Campinas: Universidade Estadual de Campinas; 2009. $146 f$.

19. Fonseca VJM. Acidente do trabalho e suas repercussóes no processo trabalhista. Jurisprudência Brasileira Trabalhista. Curitiba: Juruá; 2003. 17p.

20. Souza MAP. Acidentes de trabalho envolvendo mãos: casos atendidos em um serviço de reabilitação. Fisioter Pesq 2008;15(1):64-71.

21. Nobre HB. Os acidentes de trabalho em prensas analisados pelos auditores fiscais do trabalho do Ministério do Trabalho e Emprego no período de 2001 a 2006. [Dissertação]. Botucatu: Universidade Estadual Paulista; $2009.199 \mathrm{f}$. 